\section{Prognosis of Cancer Patients in the ICU: Much Work Remains}

\section{To the Editor:}

As intensivists who are especially concerned for patients with cancer in the ICU, we have read with great interest the study by Rosa et al ${ }^{1}$ published in the May issue of the Journal. We would like to congratulate the authors for conducting this study in a tertiary referral hospital where many patients with cancer are referred and receive care daily.

The data on the results of ICU care in subjects with cancer are mostly the result of studies conducted in cancer centers or cooperative groups that are especially involved in the care of such patients, like the study group we are participating in (Groupe de Recherche en Réanimation Respiratoire en Onco-Hématologie, http://www.grrroh. com/, Accessed May 22, 2017). They are representative of selected teams and thus may only demonstrate a volume effect as previously described (eg, in some patients with cancer suffering from acute respiratory failure, septic shock, or other comorbidities). ${ }^{2-4}$ However, Soares et $\mathrm{al}^{5}$ retrospectively reviewed 9,946 subjects with cancer (solid: 8,956 [90\%]; hematological: 990 [10\%]) admitted to 70 ICUs (51 [72.9\%] located in general hospitals and 19 [27.1\%] in cancer centers) during 2013 (medical admission: 5,017 [50.4\%]; urgent surgery admissions: 483 [4.9\%]; elective surgery admissions: 4,446 [44.7\%]). Most importantly, the authors found that ICU admissions in cancer centers were not associated with lower ICU mortality, hospital mortality, or better resource utilization when compared with ICU admissions in general hospitals.
This is an argument, among others, against the establishment of specialized ICUs, at least for oncology patients, such as those admitted for management after elective surgery. This remains to be determined for hematological patients, for whom there may be a potential benefit. ${ }^{6}$

We believe that other elements need to be clarified and commented upon. The first concerns the epidemiology of patients suffering from cancer hospitalized in ICUs. The study by Taccone et $\mathrm{al}^{7}$ is dated (subjects included in the SOAP study, which collected a large amount of data on all subjects admitted to general [non-specialized] ICUs during a 2-week period [between May 1 and 15, 2002]). To the best of our knowledge, there are no data for hematological patients, except for those in the study by Taccone et al. ${ }^{7}$ Epidemiology of cancer patients is most clear for those suffering from solid tumors, especially in the study of Puxty et $\mathrm{al}^{8}$ performed in Scotland. A total of 118,541 subjects met the inclusion criteria in this study conducted between 2000 and 2009. Overall, 6,116 subjects $(5.2 \%$ [95\% CI $5.0-5.3 \%]$ ) developed a critical illness and were admitted to the ICU within $2 \mathrm{y}$. This percentage is less than that found in a previous study in the same subjects by Bos et $\mathrm{al}^{9}(140,154$ subjects with unplanned ICU admission between January 2007 and January 2011; solid cancers: $10.9 \%$ of all ICU subjects).

We believe that future studies must not include subjects with hematological and solid cancers together and that the term cancer patient should be abandoned. The worst in-ICU prognosis of solid cancer, except those admitted in the ICU after planned surgery, patients was demonstrated several years ago and in a large study ${ }^{10}$ of approximately 36,860 subjects with cancer. The research was conducted between 2006 and 2011 in 4 hospitals in the Netherlands linked to the Dutch National Intensive Care Evaluation registry, among whom 2,374 (6.4\%) were admitted to the ICU.7,11 In this study, the long-term prognosis (evaluated after 30 , 365 , and $730 \mathrm{~d}$ of ICU admission) was better for hematological subjects. The largest study on subjects with solid cancer retrospectively analyzed the unplanned admissions of 12,290 subjects in 80 ICUs in the Netherlands over a 4-y period. ${ }^{9}$ Approximately $59.3 \%$ of all admissions were surgical (albeit unplanned), and these had a mortality rate $(9.0 \%$ vs $8.9 \%$ in the ICU and $17.4 \%$ vs $14.6 \%$ in the hospital) like that of subjects with no diagnosis of cancer. In patients with solid tumors, efforts must be made to differentiate the prognosis of those admitted to the ICU after planned surgery and others (emergency surgery, medical conditions, or securing an act for diagnostic or therapeutic purposes). The distinction between the in-ICU and in-hospital prognosis between these subgroups of subjects with solid cancer was made several years ago by Soares et al. ${ }^{12}$

Management in the ICU may be very different, especially for the decision of withholding or withdrawing active therapies after an ICU trial. Recent data suggest that these decisions may be sure after $1-3 \mathrm{~d}$ in oncological patients, but only after $7 \mathrm{~d}$ in hematological ones. ${ }^{13}$ Also, Rosa et al $^{1}$ do not report in their study one of the strongest determinants, which is Eastern Cooperative Oncology Group performance status, as recently confirmed, for survival in the ICU and after discharge. ${ }^{14,15}$

Table 1. Studies Reporting Rate of Anti-Tumoral Therapies After ICU Discharge

\begin{tabular}{|c|c|c|c|c|c|c|c|c|}
\hline Reference & Cancer & $N$ & Years & $\begin{array}{c}\text { In-ICU } \\
\text { Survival (\%) }\end{array}$ & $\begin{array}{c}\text { In-Hospital } \\
\text { Survival }(\%)\end{array}$ & $\begin{array}{c}\text { 6-Month } \\
\text { Survival (\%) }\end{array}$ & $\begin{array}{c}\text { Anti-Tumoral } \\
\text { Therapy After } \\
\text { ICU }(\%)\end{array}$ & $\begin{array}{c}\text { Modification of } \\
\text { Initial Anti-Tumoral } \\
\text { Therapy After ICU }\end{array}$ \\
\hline Roques etal (2009) ${ }^{16}$ & $\mathrm{BPC}$ & 105 & 1997-2006 & 57 & 45.7 & 27.6 & 62.5 & NR \\
\hline Andrejak etal (2011) ${ }^{17}$ & $\mathrm{BPC}$ & 76 & 1996-2006 & 52.6 & 48.7 & 13.2 & 10.8 & NR \\
\hline Bonomi etal $(2012)^{18}$ & $\mathrm{BPC}$ & 1,134 & $1992-2005$ & NR & 66.8 & 27.1 & 18.9 & NR \\
\hline Kim etal $(2014)^{19}$ & $\mathrm{BPC}$ & 95 & 2009-2011 & NR & 22.1 & NR (1-y survival 10\%) & 52.4 & NR \\
\hline Soares etal $(2014)^{4}$ & $\mathrm{BPC}$ & 449 & 2011 & 72 & 61.2 & 45.2 & 50.2 & 34.3 \\
\hline Razazi etal $(2015)^{20}$ & $\mathrm{BPC}$ & 125 & $1995-2010$ & 83 & 68.8 & 47.5 (1-y survival: $30 \%)$ & 69.8 & NR \\
\hline Camus etal $(2015)^{21}$ & Colorectal & 89 & 2003-2012 & NR & 20.4 & NR & 69 & 31 \\
\hline Auclin etal $(2017)^{22}$ & $\begin{array}{l}\text { Mixed solid } \\
\text { tumors }\end{array}$ & 262 & 2009-2014 & 66.4 & 56.1 & NR (90-d survival: $48.1 \%$ ) & 52.7 & NR \\
\hline
\end{tabular}


We fully agree with the authors that the field of research on patients with cancer admitted to ICU is still wide. Among the questions unanswered, 2 of the major elements likely to be evaluated are the possibility of reintegrating an optimal anti-neoplastic project after a stay in the ICU and the quality of life. The first element has been reported to date only in 8 studies with incomplete data, often coming from very small subtypes of subjects with cancer (Table 1). Only 2 imperfect studies report quality of life of subjects with cancers after ICU discharge. ${ }^{14,23}$ The decrease in quality of life may not be related to the fact that these patients have cancer but may simply relate to the ICU stay, as suggested in a large multi-center, prospective cohort study. ${ }^{24}$ It must finally be remembered that all of these data are valid only in developed or developing countries, where ICU beds are numerous and where the medical care of such patients is possible, mainly because the care is probably more expensive than that of other ICU patients (transfusions, antibiotics, antifungals, hematopoietic growth factors, etc.). ${ }^{25}$

We believe, as do Rosa et al, ${ }^{1}$ that critical care is essential in the supportive care of patients with cancer, sometimes even in those requiring palliative care. ${ }^{26,27} \mathrm{As}$ concluded by Bos et al, ${ }^{11}$ we believe that despite the fact that 1 of 16 cancer patients was admitted to an ICU, ICU support for this group should not be considered futile. However, other studies seem necessary to better define their prognosis in the short, medium, and long term, with careful being taken to include only patients who are comparable (ie, oncology vs hematological ones, admission after planned surgery vs others) before definitive conclusions can be made.

François Vincent MD Soufia Ayed MD Abdelaziz Bouguerba MD Sondes Yaacoubi MD Caroline Bornstain MD

Polyvalent Intensive Care Unit Groupe Hospitalier Intercommunal Le-Raincy Montfermeil Montfermeil, France

The authors have disclosed no conflicts of interest.

DOI: $10.4187 /$ respcare. 05724

\section{REFERENCES}

1. Rosa RG, Tonietto TF, Duso BA, Maccari JG, de Oliveira RP, Rutzen W, et al. Mortality of adult critically ill subjects with cancer. Respir Care 2017;62(5):615-622.

2. Zuber B, Tran TC, Aegerter P, Grimaldi D, Charpentier J, Guidet B, et al. Impact of case volume on survival of septic shock in patients with malignancies. Crit Care Med 2012;40(1):55-62.

3. Lecuyer L, Chevret S, Guidet B, Aegerter P, Martel P, Schlemmer B, Azoulay E. Case volume and mortality in haematological patients with acute respiratory failure. Eur Respir J 2008;32(3):748-754.

4. Soares M, Toffart AC, Timsit JF, Burghi G, Irrázabal C, Pattison N, et al. Intensive care in patients with lung cancer: a multinational study. Ann Oncol 2014;25(9): 1829-1835.

5. Soares M, Bozza FA, Azevedo LC, Silva UV, Corrêa TD, Colombari F, et al. Effects of organizational characteristics on outcomes and resource use in patients with cancer admitted to intensive care units. J Clin Oncol 2016;34(27):3315-3324.

6. Azoulay E, Pène F, Darmon M, Lengliné E, Benoit D, Soares M, et al. Managing critically Ill hematology patients: time to think differently. Blood Rev 2015;29(6): 359-367.

7. Taccone FS, Artigas AA, Sprung CL, Moreno R, Sakr Y, Vincent JL. Characteristics and outcomes of cancer patients in European ICUs. Crit Care 2009;13(1):R15.

8. Puxty K, McLoone P, Quasim T, Sloan B, Kinsella J, Morrison DS. Risk of critical illness among patients with solid cancers: a population-based observational study. JAMA Oncol 2015;1(8):1078-1085.

9. Bos MM, de Keizer NF, Meynaar IA, Bakhshi-Raiez F, de Jonge E. Outcomes of cancer patients after unplanned admission to general intensive care units. Acta Oncol 2012;51(7):897-905.

10. Staudinger T, Stoiser B, Müllner M, Locker GJ, Laczika K, Knapp S, et al. Outcome and prognostic factors in critically ill cancer patients admitted to the intensive care unit. Crit Care Med 2000;28(5):1322-1328.

11. Bos MM, Verburg IW, Dumaij I, Stouthard J, Nortier JW, Richel D, et al. Intensive care admission of cancer patients: a comparative analysis. Cancer Med 2015;4(7): 966-976.

12. Soares M, Silva UV, Teles JM, Silva E, Caruso P, Lobo SM, et al. Validation of four prognostic scores in patients with cancer admitted to Brazilian intensive care units: results from a prospective multicenter study. Intensive Care Med 2010;36(7):1188-1195.

13. Shrime MG, Ferket BS, Scott DJ, Lee J, Barragan-Bradford D, Pollard T, et al. Time-limited trials of intensive care for critically ill patients with cancer: how long is long enough? JAMA Oncol 2016;2(1):76-83.

14. Normilio-Silva K, de Figueiredo AC, Pedroso-de-Lima AC, Tunes-da-Silva G, Nunes da Silva A, Delgado Dias Levites A, et al. Long-term survival, quality of life, and quality-adjusted survival in critically ill patients with cancer. Crit Care Med 2016; 44(7):1327-1337.

15. Christodoulou C, Rizos M, Galani E, Rellos K, Skarlos DV, Michalopoulos A. Performance status (PS): a simple predictor of short-term outcome of cancer patients with solid tumors admitted to the intensive care unit (ICU). Anticancer Res 2007;27(4C): 2945-2948.

16. Roques S, Parrot A, Lavole A, Ancel PY, Gounant V, Djibre M, Fartoukh M. Sixmonth prognosis of patients with lung cancer admitted to the intensive care unit. Intensive Care Med 2009;35(12):2044-2050.

17. Andréjak C, Terzi N, Thielen S, Bergot E, Zalcman G, Charbonneau P, Jounieaux V. Admission of advanced lung cancer patients to intensive care unit: a retrospective study of 76 patients. BMC Cancer 2011;11:159.

18. Bonomi MR, Smith CB, Mhango G, Wisnivesky JP. Outcomes of elderly patients with stage IIIB-IV non-small cell lung cancer admitted to the intensive care unit. Lung Cancer 2012;77(3):600-604.

19. Kim YJ, Kim MJ, Cho YJ, Park JS, Kim JW, Chang H, et al. Who should be admitted to the intensive care unit? The outcome of intensive care unit admission in stage IIIB-IV lung cancer patients. Med Oncol 2014;31(3):847.

20. Razazi K, Parrot A, Khalil A, Djibre M, Gounant V, Assouad J, et al. Severe haemoptysis in patients with nonsmall cell lung carcinoma. Eur Respir J 2015;45(3):756-764.

21. Camus MF, Ameye L, Berghmans T, Paesmans M, Sculier JP, Meert AP. Rate and patterns of ICU admission among colorectal cancer patients: a single-center experience. Support Care Cancer 2015;23(6): 1779-1785.

22. Auclin E, Charles-Nelson A, Abbar B, Guérot E, Oudard S, Hauw-Berlemont C, et al. Outcomes in elderly patients admitted to the intensive care unit with solid tumors. Ann Intensive Care 2017;7(1):26.

23. Oeyen SG, Benoit DD, Annemans L, Depuydt PO, Van Belle SJ, Troisi RI, et al. Long-term outcomes and quality of life in critically ill patients with hematological or solid malignancies: a single center study. Intensive Care Med 2013;39(5):889-898.

24. Brummel NE, Bell SP, Girard TD, Pandharipande PP, Jackson JC, Morandi A, et al. Frailty and subsequent disability and mortality among patients with critical illness. Am J Respir Crit Care Med 2017; 196(1):64-72. 
25. Gopal S, Wood WA, Lee SJ, Shea TC, Naresh KN, Kazembe PN, et al. Meeting the challenge of hematologic malignancies in sub-Saharan Africa. Blood 2012;119(22): 5078-5087.

26. Azoulay E, Demoule A, Jaber S, Kouatchet A, Meert AP, Papazian L, Brochard L. Palliative noninvasive ventilation in patients with acute respiratory failure. Intensive Care Med 2011;37(8):1250-1257.

27. Merceron S, Canet E, Lemiale V, Azoulay E. Palliative vasoactive therapy in patients with septic shock. Chest 2014;146(3):e107-e108.

\section{Prognosis of Cancer Patients in the ICU: Much Work Remains-Reply}

In reply:

We read with great interest the excellent comments of Vincent et al regarding the mortality of adult critically ill subjects with cancer. The prognosis of patients with malignancies admitted to the ICU has improved considerably in the last 4 decades due to the evolution of critical care and supportive oncology. ${ }^{1}$ This trend is observed not only in patients with solid cancers, but also in patients with hematological malignancies. The $80 \%$ ICU mortality rate found in studies of the 1980s and $1990 \mathrm{~s}^{2-5}$ has decreased to values around $30-40 \%$ today. ${ }^{6,7}$ Consequently, the current ICU mortality rates of cancer patients are comparable with those of patients without cancer admitted to general ICUs. ${ }^{8}$ The mere use of the diagnosis of cancer as a reason to refuse ICU treatment is no longer acceptable, and new approaches should be developed with the aim to match the potential benefit of critical care with the needs and perspectives of cancer patients and their families.

Unfortunately, in our study ${ }^{9}$ we did not compare the mortality rates of patients with solid neoplasms with those with hematological neoplasms, and this remains as an evidence gap due to the scarce literature about this issue. Some studies have shown that subjects with hematological malignancies have higher ICU mortality rates when compared with subjects with solid cancers. ${ }^{8}$ However, conflicting data exist about this finding. For example, Azoulay et al, ${ }^{10}$ in a prospective multi-center cohort of 1,011 critically ill subjects with hematological malignancies, showed a hospital survival rate of $60 \%$, a statistic similar to those found in a mixed population of ICU patients. ${ }^{11}$ The study of van Vliet et al ${ }^{12}$ showed that the
ICU mortality rate of subjects with solid neoplasms was comparable with the rate for those with hematological tumors. Moreover, some evidence suggests that the accumulation of organic dysfunction during ICU stay is a better predictor of mortality than the type of malignancy per se. The publication of Soares et $\mathrm{al}^{6}$ on 700,000 critically ill subjects with cancer showed that mortality was predicted by severity of organ failures and performance status and not by cancer-related characteristics, such as the type of malignancy and neutropenia.

For these reasons, we agree with Vincent et al that more studies are necessary to evaluate the course of different cancer subtypes during critical illness. Cancer is a heterogeneous group of diseases, and the prognostic model of ICU mortality for cancer patients would be improved by refinements related to the interaction between the critical illness and specific characteristics of each cancer subtype. Confounding factors, such as type of ICU admission (medical, emergency surgery, or elective surgery), time between ICU indication and ICU admission, performance status before ICU admission, degree of organ dysfunction during ICU stay, optimal cancer therapy, and rates of withdrawal and withholding support therapy during ICU stay, must be controlled to obtain improved estimates of specific cancer subtype effects on the course of critical illness. In addition, long-term outcomes, such as the incidence of post-intensive care syndrome among patients (ie, depression, anxiety, posttraumatic stress disorder, cognitive impairment, physical impairment) and their families (ie, depression, anxiety, posttraumatic stress disorder), should be evaluated for a more complete analysis of the impact of critical care on this specific population of patients. Surviving the critical illness is just the first step; we must evolve to improve long-term of quality of life cancer patients admitted to the ICU and their families.

\section{Tulio Frederico Tonietto MD Cassiano Teixeira MD PhD \\ Regis Goulart Rosa MD MSc PhD Intensive Care Unit Hospital Moinhos de Vento Porto Alegre, Brazil}

The authors have disclosed no conflicts of interest.

DOI: $10.4187 /$ respcare.05784

\section{REFERENCES}

1. Pène $F$, Percheron $S$, Lemiale V, Viallon V, Claessens YE, Marqué S, et al. Temporal changes in management and outcome of septic shock in subjects with malignancies in the intensive care unit. Crit Care Med 2008;36(3):690-696.

2. Carlon GC. Admitting cancer patients to the intensive care unit. Crit Care Clin 1988; 4(1):183-191.

3. Schuster DP, Marion JM. Precedents for meaningful recovery during treatment in a medical intensive care unit: outcome in patients with hematologic malignancy. Am J Med 1983;75(3):402-408.

4. Lloyd-Thomas AR, Wright I, Lister TA, Hinds CJ. Prognosis of patients receiving intensive care for life-threatening medical complications of haematological malignancy. BMJ 1988;296(6628):10251029.

5. Peters SG, Meadows JA 3rd, Gracey DR. Outcome of respiratory failure in hematologic malignancy. Chest 1988;94(1):99-102.

6. Soares M, Caruso P, Silva E, Teles JM, Lobo SM, Friedman G, et al. Characteristics and outcomes of subjects with cancer requiring admission to intensive care units: a prospective multicenter study. Crit Care Med 2010;38(1):9-15.

7. Darmon M, Thiery G, Ciroldi M, de Miranda S, Galicier L, Raffoux E, et al. Intensive care in patients with newly diagnosed malignancies and a need for cancer chemotherapy. Crit Care Med 2005;33(11): 2488-2493.

8. Taccone FS, Artigas AA, Sprung CL, Moreno R, Sakr Y, Vincent JL. Characteristics and outcomes of cancer subjects in European ICUs. Crit Care 2009;13(1):R15.

9. Rosa RG, Tonietto TF, Duso BA, Maccari JG, de Oliveira RP, Rutzen W, et al. Mortality of adult critically ill subjects with cancer. Respir Care 2017;62(5):615-622.

10. Azoulay E, Mokart D, Pène F, Lambert J, Kouatchet A, Mayaux J, et al. Outcomes of critically ill patients with hematologic malignancies: prospective multicenter data from France and Belgium-a Groupe de Recherche Respiratoire en Reanimation OncoHematologique study. J Clin Oncol 2013; 31(22):2810-2818.

11. Bellani G, Laffey JG, Pham T, Fan E, Brochard L, Esteban A, et al. Epidemiology, patterns of care, and mortality for patients with acute respiratory distress syndrome in intensive care units in 50 countries. JAMA 2016;315(8):788-800.

12. van Vliet M, Verburg IW, van den Boogaard M, de Keizer NF, Peek N, Blijlevens NM, Pickkers $\mathrm{P}$. Trends in admission prevalence, illness severity and survival of haematological patients treated in Dutch intensive care units. Intensive Care Med 2014;40(9):1275-1284. 